\title{
Electrocardiograph Simulator Berbasis Mikrokontroler
}

\author{
I Dewa Gede Budi Whinangun\#, Andjar Pudji, M. Ridha Makruf, Bedjo Utomo, Sari Luthfiyah \\ Jurusan Teknik Elektromedik Poltekkes Kemenkes, Surabaya \\ Jl. Pucang Jajar Timur No. 10, Surabaya, 60245, Indonesia \\ "budiwhinangun@gmail.com, andjar@poltekkesdepkes-sby.ac.id,m.reedha@gmail.com,
}

\begin{abstract}
Abstrak - Electrocardiograph (ECG) menjadi salah satu ilmu diagnostik yang sering dipelajari dalam mendiagnosis dan untuk terapi penyakit jantung. Mengingat pentingnya alat ECG recorder, maka diperlukan pengecekan fungsi alat ECG recorder yaitu dengan cara melakukan prosedur kalibrasi alat menggunakan Phantom ECG. Tujuan dari penelitian ini adalah membuat ECG Simulator untuk alat ECG 12 channel yang meliputi lead I, lead II, lead III, aVR, aVF, aVL, V1, V2, V3, V4, V5, dan V6 dan melengkapinya dengan selektor pemilihan sensitivitas serta menggunakan. Metode pembentukan sinyal jantung menggunakan DAC tipe MCP 4921 dengan mikrokontroler Atmega2560 dan untuk tampilan pengaturanya menggunakan LCD Karakter 2x16. Berdasarkan hasil pengukuran didapat nilai tingkat kesalahan sebesar $0.187 \%$ sensitivitas $0.5 \mathrm{mV}$ dan $0.327 \%$ sensitivitas $1.0 \mathrm{mV}$ pada setting BPM 30, didapat nilai tingkat kesalahan sebesar $1.173 \%$ sensitivitas $0.5 \mathrm{mV}$ dan $1.060 \%$ sensitivitas $1.0 \mathrm{mV}$ pada setting BPM 60, didapat nilai tingkat kesalahan sebesar $0.797 \%$ sensitivitas $0.5 \mathrm{mV}$ dan $0.739 \%$ sensitivitas $1.0 \mathrm{mV}$ pada setting BPM 120, didapat nilai tingkat kesalahan sebesar $0.269 \%$ sensitivitas $0.5 \mathrm{mV}$ dan $0.381 \%$ sensitivitas $1.0 \mathrm{mV}$ pada setting BPM 180 dan $0.010 \%$ sensitivitas $0.5 \mathrm{mV}$ dan $0.616 \%$ sensitivitas $1.0 \mathrm{mV}$ pada setting BPM 240. Modul ECG Simulator dilengkapi dengan fitur charge baterai dan biaya pembuatan yang lebih murah dibandingkan dengan alat pabrikan.
\end{abstract}

Keywords—BPM; Sensitivitas; ECG Simulator

\section{Pendahuluan}

Electrocardiograph (ECG) pertama kali ditemukan oleh Einthoven (1904). ECG menjadi salah satu ilmu diagnostik yang sering dipelajari dalam penyembuhan modern, salah satunya untuk mendiagnosis dan untuk terapi penyakit yang disebabkan oleh jantung dengan memanfaatkan visualisasi rekaman sinyal ECG. Pemahaman tentang bentuk sinyal dari alat ECG diperlukan dalam mempelajari alat. Berhubungan dengan hal tersebut, maka diperlukan suatu alat yang mampu mensimulasikan sinyal tubuh manusia yang dapat membantu dalam proses pembelajaran. ECG Simulator atau biasa disebut Phantom ECG pada prinsipnya merupakan suatu generator sinyal dengan bentuk sinyal "ECG like" atau sinyal ECG yang telah terekam. Perangkat ini berguna untuk pengetesan perangkat ECG pada saat pemeliharaan dan perbaikan. Perangkat ini bisa direalisasikan berbasis mikrokontroler, rangkaian analog biasa atau berbasis $\mathrm{PC}[1]$.

Pada penelitian sebelumnya ECG Simulator sudah pernah dibuat oleh Candan Caner dengan judul "The Programable ECG Simulator" dalam penelitian Candan Caner Phantom ECG menggunakan PIC mikrokontroler dan DAC MCP4922. Pada penelitian tersebut pemilihan Heart Rate hanya mencapai 120 BPM. Pada tahun 2014 juga dilakukan penelitian oleh Valais tentang "Design and Construction of a Prototype ECG Simulator", dengan menggunakan Atmega 8515 dan diperoleh range Heart Rate 60-180 BPM [2]. Sedangkan di Kampus Teknik Elektromedik ECG Simulator pernah dibuat oleh
Gregorius Mario Tani pada tahun 2017 dengan judul Simulator ECG (Phantom Electrocardiograph). Metode yang digunakan adalah menggunakan IC Digital To Analog (DAC) tipe MCP43921 untuk membentuk sinyal jantung yang diinginkan. Menurut data hasil penelitian didapatkan pengukuran BPM 90 memiliki nilai error sebesar 4,13\%, pada BPM 60 nilai error sebesar 3,9\% dan pada BPM 110 memiliki error sebesar 2,63\%. Alat tersebut hanya memiliki nilai heart rate dengan rentang 30110 Beat Per Minute[3]. Selanjutnya tahun 2017 Ni Nyoman Sri Malini juga membuat alat ECG Simulator menggunakan pembentukan sinyal ECG dengan IC counter 4017 serta clock NE555. Berbeda dengan IC DAC yang dapat dibentuk sesuai plotting gambar asli dari sinyal jantung, sedangkan IC counter 4017 yang digunakan Ni Nyoman Sri Malini masih memiliki kelemahan pada penggunaan kapasitor, sehingga menyebabkan bentuk gelombang ECG yang kurang sempurna pada segmen S$\mathrm{T}$ serta besar nilai kapasitor berpengaruh terhadap lebar segmen dan interval pada gelombang PQRST. ECG Simulator tersebut memiliki rentang BPM $30-240$. Selain hal tersebut, terkait BPM juga tampak kelemahannya pada frekuensi yang dikeluarkan oleh mikrokontroler berubah-rubah sehingga BPM tidak stabil. Untuk nilai error interval dan segmen didapat pada interval P-R memiliki error sebesar 1,86\%, pada interval QRS memiliki error sebesar $0,77 \%$ pada interval S-T error sebesar $196 \%$ serta pada interval Q-T error sebesar 7,11\%[4]. Berikutnya pada tahun 2018 ECG Simulator juga pernah dibuat oleh M. Ziko Alamanda dengan judul Phantom ECG. Metode yang digunakan adalah menggunakan IC Digital To Analog (DAC) tipe MCP4921 untuk membentuk sinyal jantung yang 
diinginkan. ECG Simulator tersebut memiliki rentang BPM 30 -240 dan terdapat pemilihan sensitivitas $0,5 \mathrm{mV}$ dan $1,0 \mathrm{mV}$. Karya ilmiah ini memiliki kelemahan pada output bidang frontal (RA, LA, LL dan RL), sehingga tidak dapat digunakan untuk mensimulasi peralatan ECG dengan lead lengkap (12 lead)[5].

Berdasarkan hasil identifikasi dari latar belakang masalah di atas, maka penulis ingin menyempurnakan alat yang sudah dibuat sebelumnya dengan membuat ECG Simulator untuk alat ECG 12 channel yang meliputi lead I, lead II, lead III, aVR, aVF, aVL, V1, V2, V3, V4, V5, dan V6, dan melengkapinya dengan selektor pemilihan sensitivitas serta menggunakan metode pembentukan sinyal jantung melalui DAC tipe MCP 4921 dengan mikrokontroler ATmega 2560. Selain itu alat yang akan dibuat juga dilengkapi dengan fitur charge baterai sehingga diharapkan menghemat biaya penggantian baterai dan biaya pembuatan yang lebih murah dibandingkan dengan alat pabrikan.

\section{BAHAN DAN METODE}

\section{A. Batasan Masalah}

Penelitian ini memiliki output 10 sadapan ECG (RA, LA, LL, RL, V1, V2, V3, V4, V5, dan V6). Sehingga dapat mengeluarkan output lead I, II, III, aVR, aVL, aVF, V1, V2, V3, V4, V5, dan V6 apabila direkam dengan ECG recorder. Selain itu terdapat pemilihan sensitivitas dengan nilai $0.5,1.0$, dan 2.0 $\mathrm{mV}$, serta memiliki rentang BPM 30, 60, 120, 180, dan 240 dengan kontrol saklar rotary.

\section{1) Alat dan Bahan}

Penelitian ini menggunakan IC DAC MCP4921 untuk pembetukan sinyalnya. Hasil ouput dari IC DAC selanjutnya di olah dengan rangkaian resistror network yang menghasilkan output 10 sadapan ECG (RA, LA, LL, RL, V1, V2, V3, V4, V5, dan V6). Sebagai display pengaturan alat ini menggukan LCD karakter 2 x 16. Hasil output dari alat ini diuji menggunakan ECG Recorder (Digital Electrocardiograph, Model : ECG9012A, SN : ECG-9012A120435). Selanjutnya ECG Simulator (Bio Tek, Model: ECGPlus, SN: 91219) digunakan sebagai alat pembanding hasil output dari alat.

\section{2) Experiment}

Dalam penelitian ini, setelah alat selesai untuk dikerjakan, hasil sinyal output alat direkam menggukan ECG Recorder. Kemudian hasil perekaman sinyal alat yang telah dibuat dibandingkan dengan ECG Simulator (Bio Tek, Model: ECGPlus, SN: 91219).

\section{B. Blok Diagram}

Saat alat dinyalakan MCU atau mikrokontroler akan menunggu perintah dari kontrol untuk pemilihan jenis gelombang dan kontrol lainnya selain itu display akan menampilkan jenis sinyal yang langsung dikeluarkan saat pertama alat dinyalakan. Sedangkan saklar rotary (BPM kontrol) akan langsung bekerja sesuai putarannya dan menyebabkan dikeluarkan bentuk sinyal pertama oleh MCU meskipun tanpa menyentuh kontrol untuk dikeluarkan menuju rangkaian Digital to Analog Converter atau DAC dalam bentuk Digital. Pemilihan bentuk sinyal dengan memutar saklar rotary akan memiliki range BPM berbeda dan kemudian juga akan ditampilkan pada display LCD 2x16. Sedangkan blok LA, RA, LL, RL, V1, V2, V3, V4, V5, dan V6 akan menerima bentuk sinyal yang dikeluarkan oleh DAC dalam bentuk Analog yang sebelumnya telah diolah dalam blok Resistor Network Circuit. Blok Resistor Network Circuit ini berfungsi untuk memberikan perbedaan impedansi pada setiap Lead.

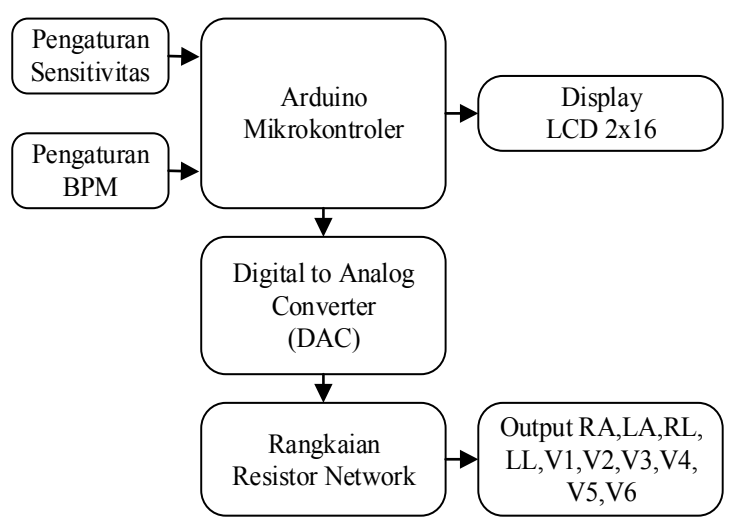

Gambar 1. Blok Diagram ECG Simulator

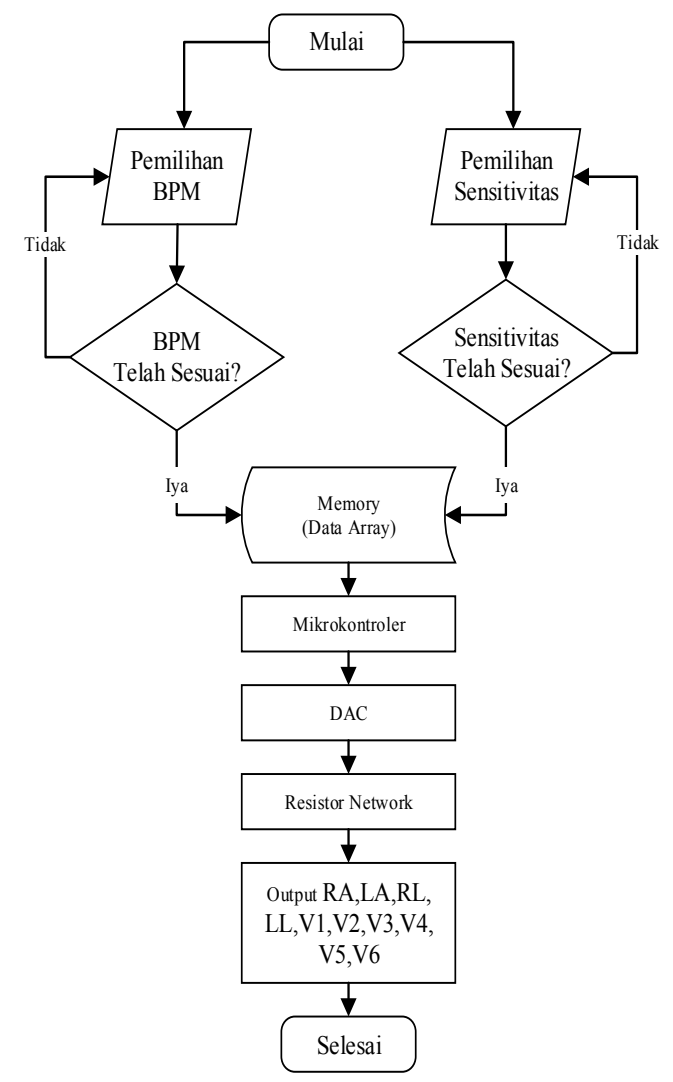

Gambar 2. Diagram Alir ECG Simulator 


\section{Diagram Alir}

Program Arduino dibangun berdasarkan diagram alir yang ditunjukkan pada Gambar 2. Setelah dimulai, program akan membaca pemilihan BPM dan sensitivitas yang dilakukan. Hasil pembacaan akan mengatur komposisi data array yang gunakan. Kemudian data array akan dikeluarkan oleh mikrokontroler dan diterima oleh DAC. Selanjutnya hasil pengolahan pada DAC akan dikeluarkan ke rangkaian resistor network yang kemudian akan dibagi menjadi 10 outputan.

\section{Rangkaian Analog}

Bagian penting dari pengembangan modul ini adalah rangkaian analog yang menggambarkan pada Gambar. 3 rangkaian digital to analog converter) dan Gambar. 4 (rangkaian resistor network). Kedua rangkaian tersebut digunakan dalam pemrosesan sinyal yang di keluarkan oleh mikrokontroler.

\section{1) Rangkaian Digital to Analog Converter (DAC)}

Rangkaian DAC merupakan rangkaian yang digunakan untuk mikrokontroler dapat berkomunikasi dengan DAC MCP4921 yaitu melalui PIN CS, SCK dan SDI. Mikrokontroler akan memberikan bentuk sinyal digital melalui program dan DAC MCP4921 akan menterjemahkan menjadi data analog dengan resolusi 12-bit. Untuk rangkaianya dapat dilihat Gambar

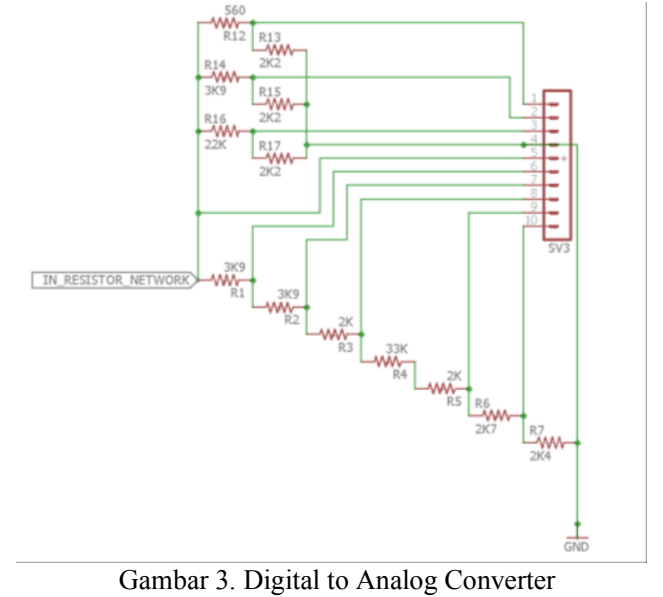

Nilai tegangan output dari DAC dapat dihitung dengan rumus berikut:

$$
\text { Vout }=\operatorname{Vref} \frac{D}{12 b i t}
$$

Selain digunakan untuk mengatur tegangan output yang berupa tegangan analog, DAC ini digunakan untuk mengatur Frekuensi atau Periode dari sinyal ECG. Perhitungannya sebagai berikut:

$$
\text { Frekuensi }(f)=\frac{\text { Heart rate }}{60 \text { detik }}
$$

Sedangkan periode didapatkan setelah kita mengetahui nilai frekuensi dari setiap BPM yang akan diukur atau sebaliknya sebagai berikut :

\section{2) Rangkaian Resistor Network}

$$
\operatorname{Periode}(T)=\frac{1}{\mathrm{f}}(3)
$$

Rangkaian ini digunakan untuk membagi nilai sinyal ECG sesuai impedansi tubuh. Berikut merupakan rincian dari pin kontektornya: $\operatorname{pin} 1=\mathrm{LA}, \operatorname{pin} 2=\mathrm{LL}, \operatorname{pin} 3=\mathrm{RA}, \operatorname{pin} 4=\mathrm{RL}$, pin5 $=\mathrm{V} 4$, pin $6=\mathrm{V} 3$, pin $7=\mathrm{V} 5$, pin8 $=\mathrm{V} 6$, pin $9=\mathrm{V} 1$, dan pin10=V2. Selanjutnya nilai sinyal di setiap pinya dapat dihitung dengan rumus ebagai berikut jika diumpamakan IN_RESISTOR_NETWORK $=$ INPUT.

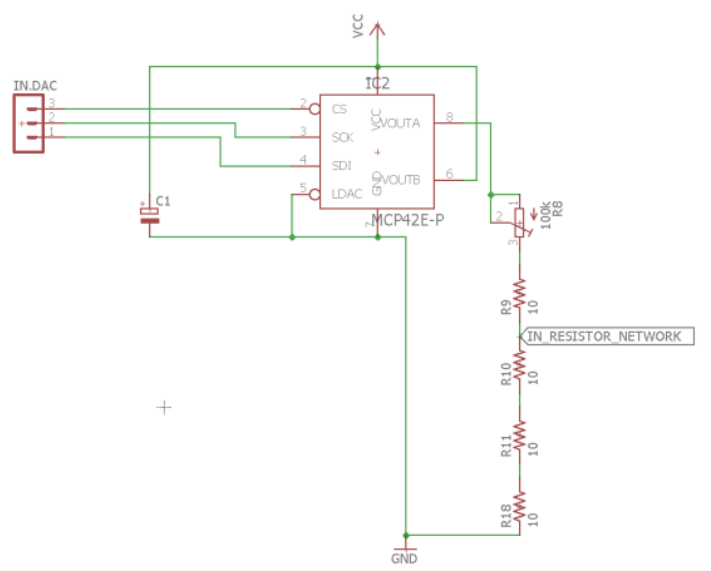

Gambar 4. Rangkaian Resistor Network

Rangkaian diatas merupakan rangkaian pembagian tegangan, dimana berikut merupakan hasil perhitungan nilai masing-masing outputnya:

$$
\begin{aligned}
V(\text { pin } 1) & =\frac{R 13}{R 12+R 13} \times \text { INPUT } \\
& =\frac{2 K 2}{560+2 K 2} \times \text { INPUT } \\
& =\frac{2 K 2}{2760} \times \text { INPUT }=0,7971014492 \times \text { INPUT } \\
V(\text { pin } 2) & =\frac{R 15}{R 14+R 15} \times \text { INPUT } \\
& =\frac{2 K 2}{3 K 9+2 K 2} \times \text { INPUT } \\
& =\frac{2 K 2}{6 K 1} \times \text { INPUT }=0,3606557377 \times \text { INPUT } \\
V(\text { pin } 3) & =\frac{R 17}{R 16+R 17} \times \text { INPUT } \\
& =\frac{2 K 2}{22 K+2 K 2} \times \text { INPUT } \\
& =\frac{2 K 2}{24 K 2} \times \text { INPUT }=0,0909090909 \times \text { INPUT } \\
V(\text { pin } 4) & =\text { GND } \\
V(\text { pin5 }) & =\mathrm{INPUT} \\
V(\text { pin6) } & =\frac{R 2+R 3+R 4+R 5+R 6+R 7}{R 1+R 2+R 3+R 4+R 5+R 6+R 7} \times \mathrm{INPUT}
\end{aligned}
$$




$$
\begin{aligned}
& =\frac{3 K 9+2 K+33 K+2 K+2 K 7+2 K 4}{3 K 9+3 K 9+2 K+33 K+2 K+2 K 7+2 K 4} \times \text { INPUT } \\
& =\frac{46 K}{49 K 9} \times \text { INPUT }=0,9218436873747495 \times \text { INPUT } \\
V(\text { pin } 7) & =\frac{R 3+R 4+R 5+R 6+R 7}{R 1+R 2+R 3+R 4+R 5+R 6+R 7} \times \text { INPUT } \\
& =\frac{2 K+33 K+2 K+2 K 7+2 K 4}{3 K 9+3 K 9+2 K+33 K+2 K+2 K 7+2 K 4} \times \text { INPUT } \\
& =\frac{42 K 1}{49 K 9} \times \text { INPUT }=0,843687374749499 \times \text { INPUT } \\
V(\text { pin } 8) & =\frac{R 4+R 5+R 6+R 7}{R 1+R 2+R 3+R 4+R 5+R 6+R 7} \\
& =\frac{33 K+2 K+2 K 7+2 K 4}{3 K 9+3 K 9+2 K+33 K+2 K+2 K 7+2 K 4} \times \text { INPUT } \\
& =\frac{40 K 1}{49 K 9} \times \text { INPUT }=0,8036072144288577 \times \text { INPUT } \\
V(\text { pin } 9) & =\frac{R 6+R 7}{R 1+R 2+R 3+R 4+R 5+R 6+R 7} \times \text { INPUT } \\
& =\frac{2 K 7+2 K 4}{3 K 9+3 K 9+2 K+33 K+2 K+2 K 7+2 K 4} \times \text { INPUT } \\
& =\frac{5 K 1}{49 K 9} \times \text { INPUT }=0,1022044088176353 \times \text { INPUT } \\
V(\text { pin } 10) & =\frac{R 7}{R 1+R 2+R 3+R 4+R 5+R 6+R 7} \times \text { INPUT } \\
& =\frac{2 K 4}{3 K 9+3 K 9+2 K+33 K+2 K+2 K 7+2 K 4} \times \text { INPUT } \\
& =\frac{2 K 4}{49 K 9} \times \text { INPUT }=0,0480961923847695 \times I N P U T \\
&
\end{aligned}
$$

\section{HASIL}

Dalam penelitian ini, ECG Simulator telah diuji menggunakan phantom ECG (BioTek, Model : ECGPlus, SN : 91219) dengan cara membandingkan hasil perekeman sinyal ECG dari ECG Recorder (Digital Electrocardiograph, Model : ECG-9012A, SN : ECG-9012A120435). Hasil perekaman menunjukan bahwa otputan ECG Simulator dan phantom ECG tidak terlalu berbeda atau masih dalam batas toleransi.

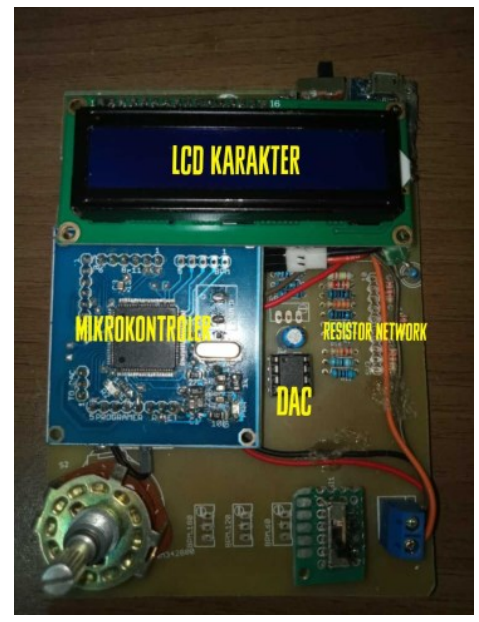

Gambar 5. The Holter ECG design

\section{1) Desain ECG Simulator}

Dari gambar diatas dapat dilihat komponen-komponen yang digunakan pada alat. Rangkaian yang pertama adalah mikrokontroller dengan menggunakan IC ATmega 2560, yang kedua rangkaian DAC (Digital To Analog Converter) menggunakan MCP4921 yang berfungsi untuk mengubah data digital dari mikrokontroller menjadi data analog.

\section{2) Listing Program ECG Simulator}

Dalam tulisan ini, pemograman diatur menggunakan arduino untuk mengatur sinyal output alat. Program terdiri dari Set Up SPI Interface (untuk mengaktifkan mode serial komunikasi SPI Interface), timer2 interrupt, pengaturan sentitivitas, pengaturan BPM, data sampel sinyal ECG, pengaturan jumlah sampel data, program perhitungan periode sampel data dengan periode diam program fungsi interrupt, program pengiriman DTOA, program tampilan LCD.

Listing program 1. Program Set Up SPI Interface

\#include "SPI.h" // supports the SPI interface to the D/A converter and 7-segment display

\#include $<$ Wire.h $>/ /$ need the Wire library

pinMode(53, OUTPUT); // D/A converter chip select (low to select chip)

pinMode(51, OUTPUT); // SDI data

pinMode(52, OUTPUT); // SCK clock

$/ /$ initial state of SPI interface

SPI.begin(); // wake up the SPI bus.

SPI.setDataMode(0); // mode: $\mathrm{CPHA}=0$, data captured on clock's rising edge (low $\rightarrow$ high)

SPI.setClockDivider(SPI_CLOCK_DIV64); // system clock / 64

SPI.setBitOrder(MSBFIRST); // bit 7 clocks out first

Listing Program 2. Program Timer2 Interrupt

// First disable the timer overflow interrupt while we're configuring

TIMSK2 \&= ( $1<<$ TOIE2 $)$;

// Configure timer2 in normal mode (pure counting, no PWM etc.)

TCCR2A $\&=\sim((1<<$ WGM21) $\mid(1<<$ WGM20 $))$;

TCCR2B $\&=\sim(1<<$ WGM 22$)$;

// Select clock source: internal I/O clock

ASSR \& $=\sim(1<<$ AS2 $)$;

// Disable Compare Match A interrupt enable (only want overflow)

TIMSK2 \&= ( $1<<$ OCIE2A);

// Now configure the prescaler to CPU clock divided by 128 TCCR2B $\mid=(1<<$ CS22 $) \mid(1<<$ CS20); / Set bits

TCCR2B $\&=\sim(1<<$ CS2 1$)$; / Clear bit

$/ /$ We need to calculate a proper value to load the timer counter.

// The following loads the value 131 into the Timer 2 counter register 


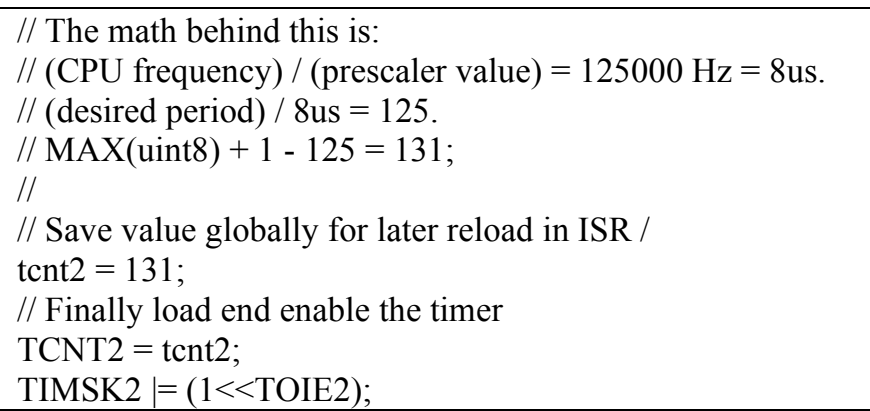

Listing Program 3. Program Pengaturan Sensitivitas

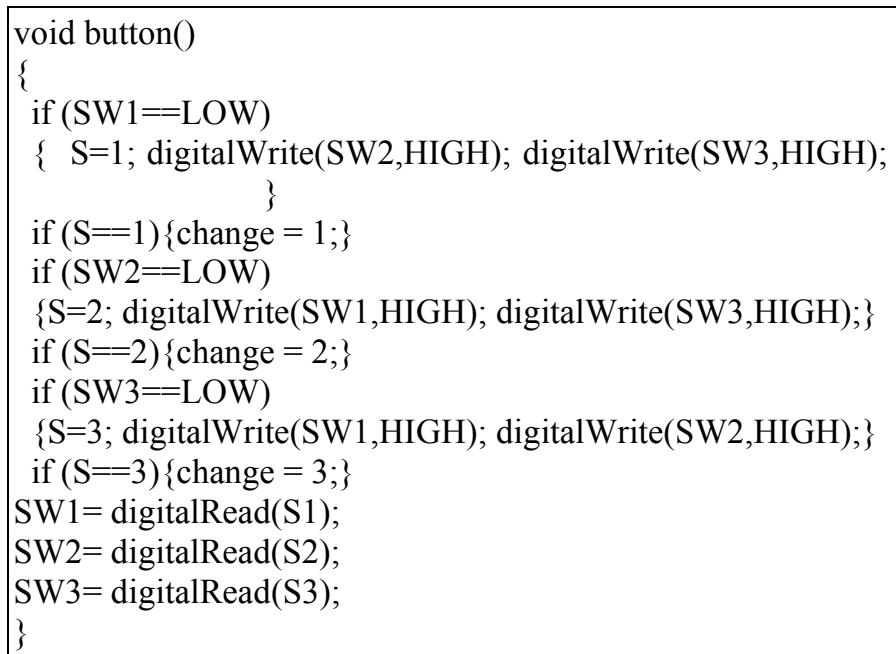

Listing Program 4. Program Pengaturan BPM

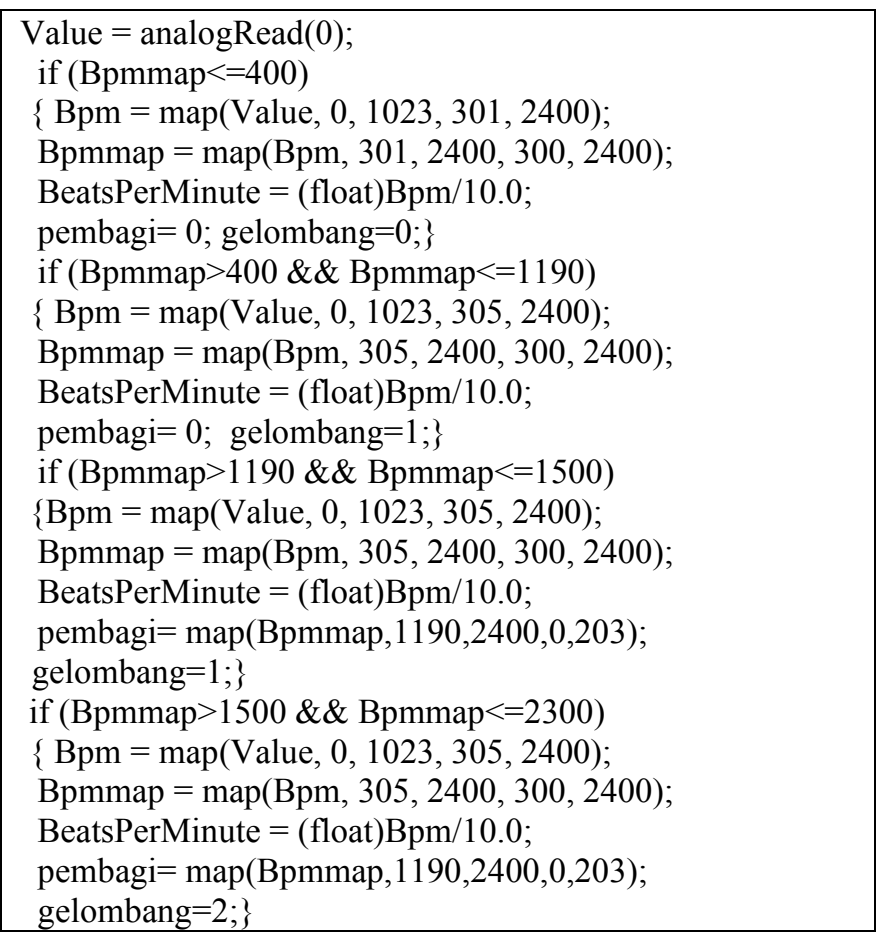

if (Bpmmap $>2300)$

$\{\mathrm{Bpm}=\operatorname{map}($ Value, $0,1023,305,2400)$;

Bpmmap $=\operatorname{map}(B p m, 305,2400,300,2400)$;

BeatsPerMinute $=$ (float $) \mathrm{Bpm} / 10.0$;

pembagi $=\operatorname{map}($ Bpmmap $, 1190,2400,0,203)$;

gelombang $=3 ;\}$

Listing Program 5. Program Data Sampel Sinyal ECG

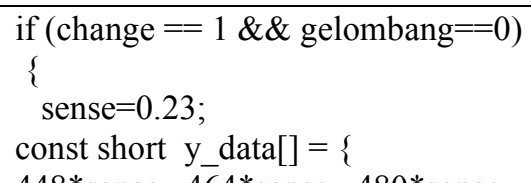

$448 *$ sense, $464 *$ sense, $480 *$ sense, $496 *$ sense, $512 *$ sense, $528 *$ sense, $544^{*}$ sense, $560^{*}$ sense, $576^{*}$ sense, $592 *$ sense, $608 *$ sense, $623 *$ sense, 634*sense, 646*sense, 658*sense, $669 *$ sense, $681 *$ sense, $692 *$ sense, $704 *$ sense, $715 *$ sense, $727 *$ sense, $739 *$ sense, $750 *$ sense, $762 *$ sense, $773 *$ sense, $78{ }^{*}$ sense, $796 *$ sense, $80 *^{*}$ sense, $820 *$ sense, $831 *$ sense, $843 *$ sense, $854 *$ sense, $866 *$ sense, $875 *$ sense, $883 *$ sense, $891 *$ sense, $898 *$ sense, $906 *$ sense, $914 *$ sense, $922 *$ sense, $929 *$ sense, $937 *$ sense, $945 *$ sense, $953 *$ sense, $960 *$ sense, $968 *$ sense, $973 *$ sense, $971 *$ sense, $970 *$ sense, $968 *$ sense, $966 *$ sense, $965 *$ sense, $963 *$ sense, $962 *$ sense, $960 *$ sense, $959 *$ sense, $957 *$ sense, $95{ }^{*}$ sense, $954 *$ sense, $952 *$ sense, $951 *$ sense, $949 *$ sense, $948 *$ sense, $946 *$ sense, $944 *$ sense, $940 *$ sense, $931 *$ sense, $922 *$ sense, $913 *$ sense, $904 *$ sense, $895 *$ sense, $886 *$ sense, $877 *$ sense, $868 *$ sense, $859 *$ sense, $850 *$ sense, $841 *$ sense, $832 *$ sense, $823 *$ sense, $814 *$ sense, $805 *$ sense, $796 *$ sense, $787 *$ sense, $778 *$ sense, $768 *$ sense, $755 *$ sense, $742 *$ sense, $729 *$ sense, $717 *$ sense, $704 *$ sense, $691 *$ sense, $678 *$ sense, 666*sense, 653*sense, 639*sense, $624 *$ sense, $609 *$ sense, $594 *$ sense, $579 *$ sense, $564 *$ sense, $549 *$ sense, $536 *$ sense, $528 *$ sense, $521 *$ sense, $514 *$ sense, $506 *$ sense, $499 *$ sense, $492 *$ sense, $484 *$ sense, $477 *$ sense, $471 *$ sense, $468 *$ sense, $466 *$ sense, $463 *$ sense, $461 *$ sense, $458 *$ sense, $456^{*}$ sense, $453 *$ sense, $451 *$ sense, $449 *$ sense, $446 *$ sense, $444 *$ sense, $441 *$ sense, $439 *$ sense, $436 *$ sense, $434 *$ sense, $431 *$ sense, $429 *$ sense, $426 *$ sense, $422 *$ sense, $419 *$ sense, $415 *$ sense, $411 *$ sense, $407 *$ sense, $403 *$ sense, $400 *$ sense, $396 *$ sense, $392 *$ sense, $388 *$ sense, $384 *$ sense, $381 *$ sense, $367 *$ sense, $353 *$ sense, $338 *$ sense, $324 *$ sense, $310 *$ sense, $296 *$ sense, $278 *$ sense, $258 *$ sense, $237 *$ sense, $217 *$ sense, $196 *$ sense, $179 *$ sense, $162 *$ sense, $156 *$ sense, $158 *$ sense, $159 *$ sense, $161 *$ sense, $189 *$ sense, $229 *$ sense, $274 *$ sense, $312 *$ sense, $348 *$ sense, $493 *$ sense, $686 *$ sense, $880 *$ sense, $1073 *$ sense, $1267 *$ sense, $1460 *$ sense, $1654 *$ sense,

$1847 *$ sense, $\quad 2041 *$ sense, $\quad 2232 *$ sense, $\quad 2415 *$ sense, $2597 *$ sense, $2728 *$ sense, $2803 *$ sense, $2878 *$ sense, $2953 *$ sense, $3024 *$ sense, $3095 *$ sense, $\quad 3166 *$ sense, $3236 *$ sense, $3275 *$ sense, $3270 *$ sense, $3266 *$ sense, $3260 *$ sense, $3252 *$ sense, $3230 *$ sense, $3186 *$ sense, 
3108*sense, 2996*sense, 2745*sense, 2589*sense, $2433 *$ sense, $\quad 2277 *$ sense, $2121 *$ sense, $1965 *$ sense, $1809 *$ sense, $1653 *$ sense,

$1497 *$ sense, $1341 *$ sense, $1185 *$ sense, $1030 *$ sense, $874 *$ sense, $718 *$ sense, $562 *$ sense, $417 *$ sense, $278 *$ sense, $182 *$ sense,

$130 *$ sense, $77 *$ sense, $25 *$ sense, $3 *$ sense, $9 *$ sense, $15 *$ sense, $21 *$ sense, $27 *$ sense, $33 *$ sense, $39 *$ sense,

$45 *$ sense, $51 *$ sense, $91 *$ sense, $135 *$ sense, $193 *$ sense, $230 *$ sense, $254 *$ sense, $278 *$ sense, $301 *$ sense, $311 *$ sense, $322 *$ sense, $332 *$ sense, $342 *$ sense, $352 *$ sense, $359 *$ sense, $367 *$ sense, $374 *$ sense, $381 *$ sense, $388 *$ sense, $394 *$ sense, $397 *$ sense, $399 *$ sense, $401 *$ sense, $404 *$ sense, $406 *$ sense, $409 *$ sense, $411 *$ sense, $413 *$ sense, $415^{*}$ sense, $415^{*}$ sense, $415^{*}$ sense, $415^{*}$ sense, $416^{*}$ sense, $416^{*}$ sense, $416^{*}$ sense, $416 *$ sense, $416 *$ sense, $417 *$ sense, $417 *$ sense, $417 *$ sense, $417 *$ sense, $418 *$ sense, $418 *$ sense, $418 *$ sense, $418 *$ sense, $419 *$ sense, $419 *$ sense, $419 *$ sense, $419 *$ sense, $419 *$ sense, $419 *$ sense, $419 *$ sense, $419 *$ sense, $419 *$ sense, $419 *$ sense, $420 *$ sense, $420 *$ sense, $420 *$ sense, $420 *$ sense, $420 *$ sense, $420 *$ sense, $420 *$ sense, $420 *$ sense, $420 *$ sense, $420 *$ sense, $421 *$ sense, $421 *$ sense, $421 *$ sense, $421 *$ sense, $421 *$ sense, $421 *$ sense, $421 *$ sense, $421 *$ sense, $421 *$ sense, $421 *$ sense, $421 *$ sense, $421 *$ sense, $421 *$ sense, $421 *$ sense, $421 *$ sense, $421 *$ sense, $421 *$ sense, $421 *$ sense, $421 *$ sense, $421 *$ sense, $421 *$ sense, $421 *$ sense, $421 *$ sense, $421 *$ sense, $421 *$ sense, $421 *$ sense, $421 *$ sense, $421 *$ sense, $421 *$ sense, $421 *$ sense, $421 *$ sense, 421 *sense, $421 *$ sense, $421 *$ sense, $421 *$ sense, $421 *$ sense, $421 *$ sense, $421 *$ sense, $421 *$ sense, $421 *$ sense, $421 *$ sense, $421 *$ sense, $421 *$ sense, $421 *$ sense, $421 *$ sense, $421 *$ sense, $421 *$ sense, $421 *$ sense, $421 *$ sense, $421 *$ sense, $421 *$ sense, $421 *$ sense, $421 *$ sense, $421 *$ sense, $421 *$ sense, $421 *$ sense, $421 *$ sense, $421 *$ sense, $421 *$ sense, $421 *$ sense, $421 *$ sense, $421 *$ sense, $421 *$ sense, $421 *$ sense, $421 *$ sense, $423 *$ sense, $425 *$ sense, $427 *$ sense, $429 *$ sense, $432 *$ sense, $434 *$ sense, $436 *$ sense, $438 *$ sense, $440 *$ sense, $442 *$ sense, $444 *$ sense, $446 *$ sense, $451 *$ sense, $457 *$ sense, $462 *$ sense, $467 *$ sense, $472 *$ sense, $477 *$ sense, $482 *$ sense, $488 *$ sense, $493 *$ sense, $498 *$ sense, $503 *$ sense, $508 *$ sense, $514 *$ sense, $519 *$ sense, $524 *$ sense, $529 *$ sense, $534 *$ sense, $539 *$ sense, $545 *$ sense, $550 *$ sense, $555 *$ sense, $560 *$ sense, $565 *$ sense, $570 *$ sense, $576 *$ sense, $581 *$ sense, $586 *$ sense, $595 *$ sense, $605 *$ sense, $614 *$ sense, $623 *$ sense, $633 *$ sense, $642 *$ sense, $651 *$ sense, $660 *$ sense, $670 *$ sense, $679 *$ sense, $688 *$ sense, $698 *$ sense, $707 *$ sense, $716 *$ sense, $725 *$ sense, $735 *$ sense, $744 *$ sense, $753 *$ sense, $762 *$ sense, $772 *$ sense, $781 *$ sense, $790 *$ sense, $800 *$ sense, $809 *$ sense, $818 *$ sense, $827 *$ sense, $837 *$ sense, $846 *$ sense, $855 *$ sense, $865 *$ sense, $874 *$ sense, $883 *$ sense, $892 *$ sense, $902 *$ sense, $911 *$ sense, $920 *$ sense, $930 *$ sense, $939 *$ sense, $948 *$ sense, $957 *$ sense, $967 *$ sense, $976 *$ sense, $984 *$ sense, $993 *$ sense, $1001 *$ sense, $1009 *$ sense, $1017 *$ sense, $1025 *$ sense, $1033 *$ sense, $1041 *$ sense, $1050 *$ sense,

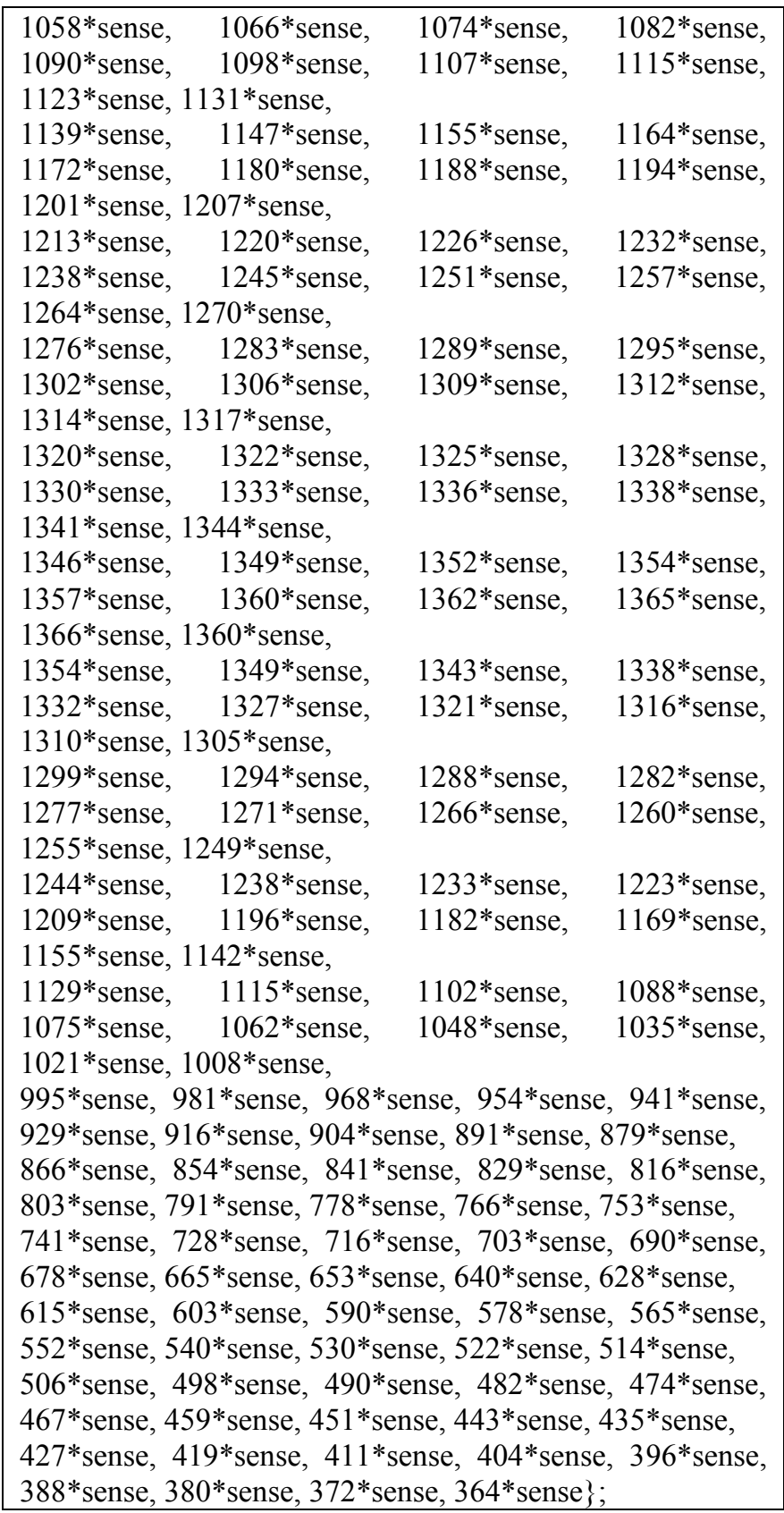

Listing Program 6. Program Pengaturan Jumlah Sampel Data

NumSamples $=\operatorname{sizeof}\left(y \_\right.$data $) /(2.00+($ pembagi $/ 100))$;

Listing Program 7. Program Perhitungan Periode Sampel Data dengan Periode Diam

BeatsPerMinute $=($ float $) \mathrm{Bpm} / 10.0$; noInterrupts(); 


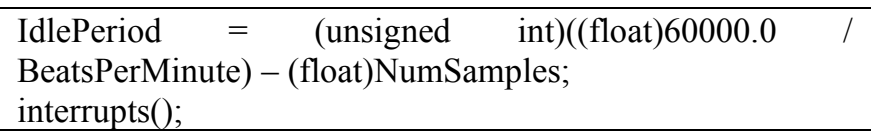

Listing Program 8. Program Fungsi Interrupt

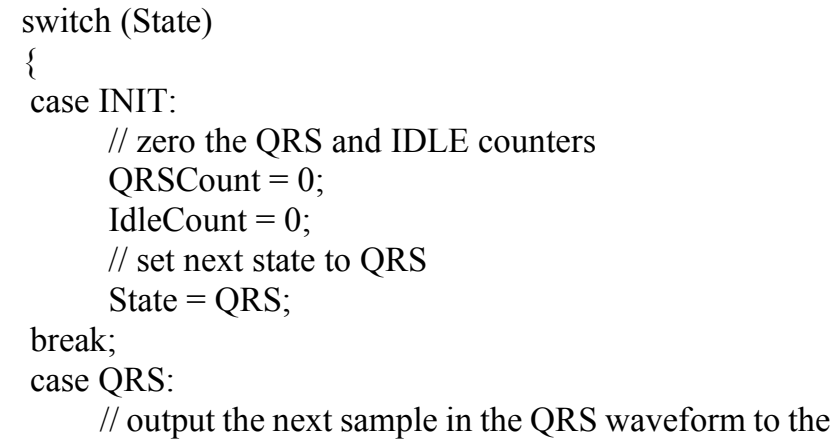

// output the next sample in the QRS waveform to the $\mathrm{D} / \mathrm{A}$ converter

DTOA_Send(y_data[QRSCount]);

// advance sample counter and check for end

QRSCount++;

if (QRSCount $>=$ NumSamples)

\{

// start IDLE period and output first sample to DTOA

QRSCount $=0$;

DTOA_Send(y_data[0]);

State = IDLE;

break;

$$
\text { \} }
$$

case IDLE:

// since $\mathrm{D} / \mathrm{A}$ converter will hold the previous value written, all we have should be.

// to do is determine how long the IDLE period

// advance idle counter and check for end

IdleCount ++ ;

// the IdlePeriod is calculated in the main loop (from a pot)

if (IdleCount $>=$ IdlePeriod)

\{

IdleCount $=0$;

State $=\mathrm{QRS}$;

break;$$
\text { \} }
$$

default:

break; \}

Listing Program 9. Program Pengiriman DTOA

void DTOA_Send(unsigned short DtoAValue)

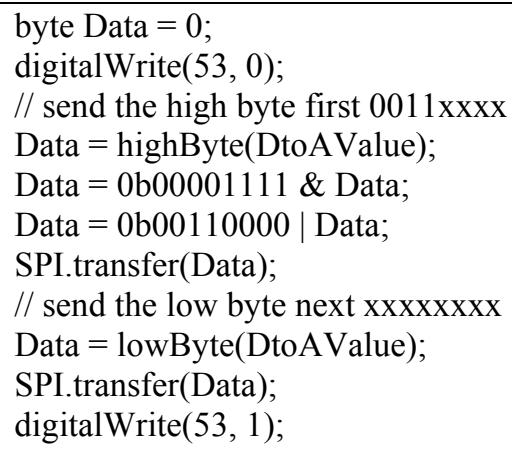

Listing Program 10. Program Tampilan LCD

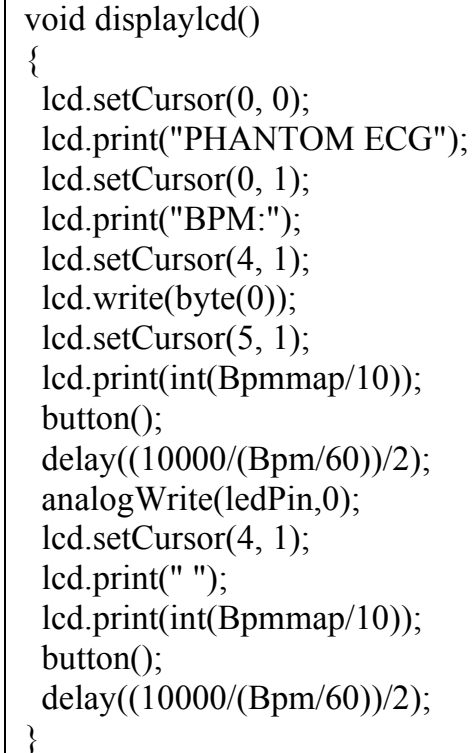

3) Sinyal ECG Simulator Dibandingkan dengan Phantom $E C G$

Berikut perbandingan hasil printout Modul ECG Simulator dan alat pembanding ECG Simulator (BioTek, Model : ECGPlus, SN : 91219). Pada kali ini hasil printout yang ditampilkan hanya hasil printout dari pengaturan BPM 180 dengan sensitivitas $2.0 \mathrm{mV}$. Pada gambar berikut sinyal ECG Simulator dengan warna line hitam dan background merah dan Modul ECG Simulator warna line putih background hitam.
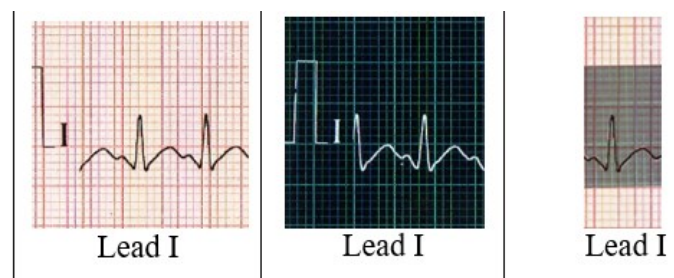

Gambar 6. Perbandingan Hasil Sinyal ECG Simulator dengan Phantom ECG (Lead I) 


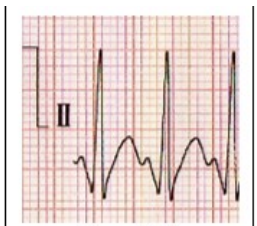

Lead II

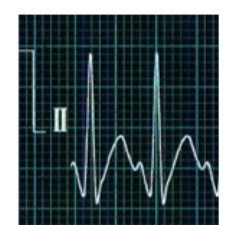

Lead II

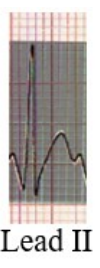

Gambar 7. Perbandingan Hasil Sinyal ECG Simulator dengan Phantom ECG (Lead II)
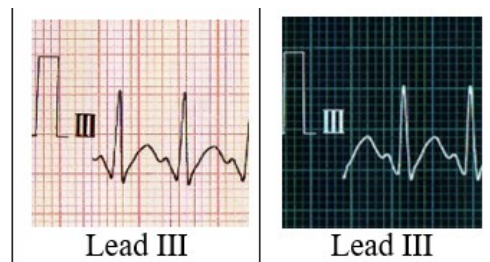

Lead III
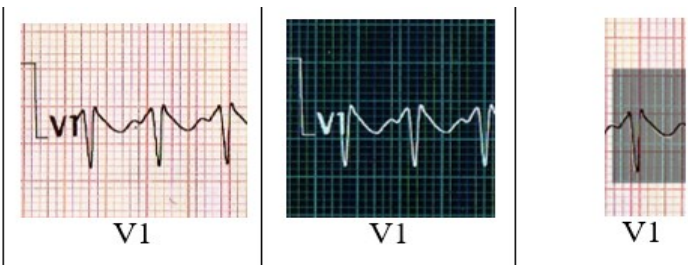

Gambar 12. Perbandingan Hasil Sinyal ECG Simulator dengan Phantom ECG (V1)
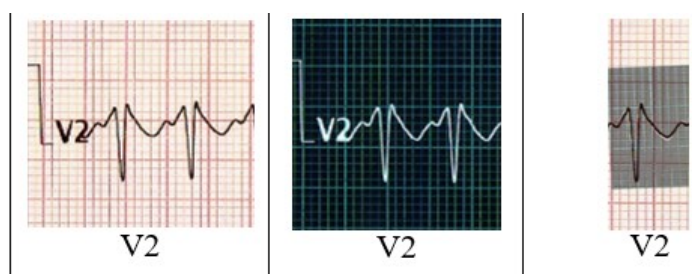

Gambar 13. Perbandingan Hasil Sinyal ECG Simulator dengan Phantom ECG (Lead V2)
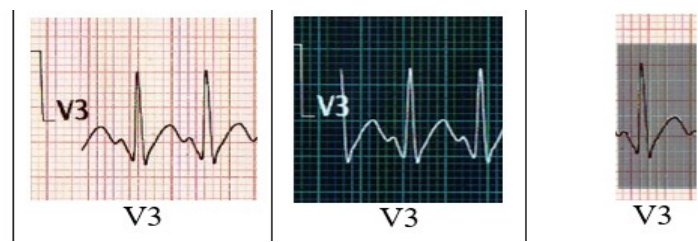

Gambar 14. Perbandingan Hasil Sinyal ECG Simulator dengan Phantom ECG (Lead V3)
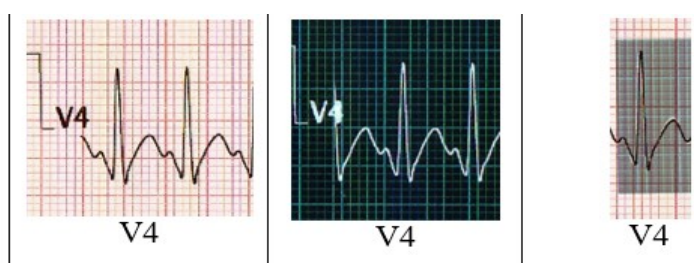

Gambar 15. Perbandingan Hasil Sinyal ECG Simulator dengan Phantom ECG (Lead V4)
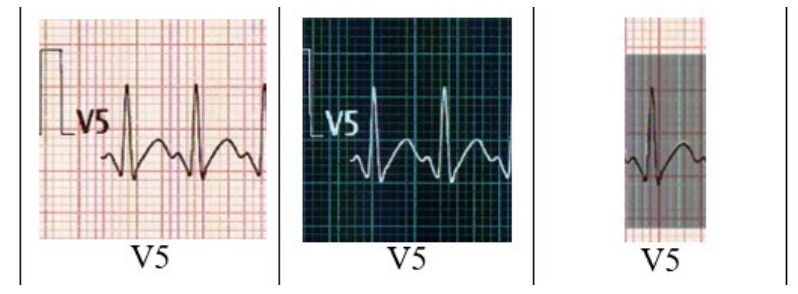

Gambar 16. Perbandingan Hasil Sinyal ECG Simulator dengan Phantom ECG (Lead V5)

Gambar 11. Perbandingan Hasil Sinyal ECG Simulator dengan Phantom ECG (Lead aVF) 

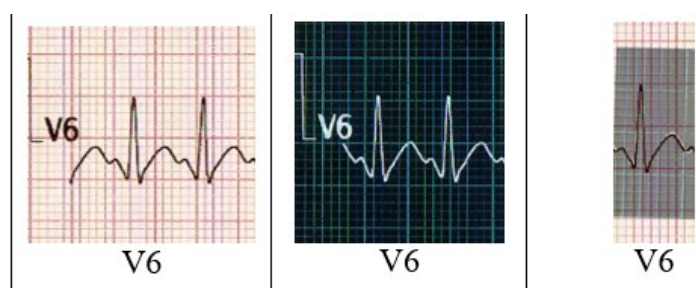

Gambar 17. Perbandingan Hasil Sinyal ECG Simulator dengan Phantom ECG (Lead V6)

\section{4) Nilai Eror BPM ECG Simulator}

Dari pengukuran hasil printout nilai BPM akan dihitung nilai errornya pada setiap setingan BPM 30, 60, 120, 180 dan 240 baik pada sensitivitas $0.5 \mathrm{mV}, 1.0 \mathrm{mV}$ dan $2.0 \mathrm{mV}$.

TABEL I. NiLAi ERROR PADA PENGatURAN SeSNitivitas 0.5MV.

\begin{tabular}{ccc}
\hline No & BPM & Error $(\%)$ \\
\hline 1 & 30 & $0.683 \%$ \\
2 & 60 & $0.562 \%$ \\
3 & 120 & $0.321 \%$ \\
4 & 180 & $0.890 \%$ \\
5 & 240 & $0.486 \%$ \\
\hline
\end{tabular}

TABEL II. Nilai ERROR Pada Pengaturan Sesnitivitas 1.0MV.

\begin{tabular}{ccc}
\hline No & BPM & Error $(\%)$ \\
\hline 1 & 30 & $0.32 \%$ \\
2 & 60 & $0.562 \%$ \\
3 & 120 & $0.16 \%$ \\
4 & 180 & $0.646 \%$ \\
5 & 240 & $0.486 \%$ \\
\hline
\end{tabular}

TABEL III. NiLAi ERRoR PADA Pengaturan Sesnitivitas 2.0MV.

\begin{tabular}{ccc}
\hline No & BPM & Error $(\%)$ \\
\hline 1 & 30 & $0.32 \%$ \\
2 & 60 & $0.643 \%$ \\
3 & 120 & $0.16 \%$ \\
4 & 180 & $0.401 \%$ \\
5 & 240 & $0.486 \%$ \\
\hline
\end{tabular}

\section{DISKUSI}

Desain ECG Simulator telah diperiksa dan diuji sepenuhnya dalam penelitian ini. Berdasarkan pengukuran output ECG Simulator dan phantom ECG, sinyal EKG yang dihasilkan ketika menggunakan input dari Simulator ECG menunjukkan pola yang benar dari sinyal EKG yang terdiri dari gelombang $\mathrm{P}$, Q, R, S, dan T dengan BPM mulai dari 30-240,dan sensitivitas $0.5 \mathrm{Mv}, 1 \mathrm{mV}$, dan $2 \mathrm{mV}$. Dengan membandingkan hasil perekaman ECG Simulator dengan phantom ECG dengan pembacaan perekaman menggunakan EKG Recorder. Kesalahan BPM antara desain dan phantom ECG (dengan pembacaan perekaman dari ECG Recorder didapat nilai tingkat kesalahan sebesar $0.683 \%$ sensitivitas $0.5 \mathrm{mV}, \quad 0.32 \%$ sensitivitas $1.0 \mathrm{mV}$, dan $0.32 \%$ sensitivitas $2.0 \mathrm{mV}$ pada setting BPM 30, didapat nilai tingkat kesalahan sebesar $0.562 \%$ sensitivitas $0.5 \mathrm{mV}, 0.562 \%$ sensitivitas $1.0 \mathrm{mV}$, dan $0.643 \%$ sensitivitas $2.0 \mathrm{mV}$ pada setting BPM 60, didapat nilai tingkat kesalahan sebesar $0.321 \%$ sensitivitas $0.5 \mathrm{mV}, \quad 0.16 \%$ sensitivitas $1.0 \mathrm{mV}$, dan $0.16 \%$ sensitivitas $2.0 \mathrm{mV}$ pada setting BPM 120, didapat nilai tingkat kesalahan sebesar $0.646 \%$ sensitivitas $0.5 \mathrm{mV}, 0.401 \%$ sensitivitas $1.0 \mathrm{mV}$, dan $0.890 \%$ sensitivitas $2.0 \mathrm{mV}$ pada setting BPM 180 dan $0.486 \%$ sensitivitas $0.5 \mathrm{mV}, 0.486 \%$ sensitivitas $1.0 \mathrm{mV}$ dan $0.486 \%$ sensitivitas $2.0 \mathrm{mV}$ pada setting BPM 240.

\section{KESIMPULAN}

Studi ini telah menunjukkan perkembangan ECG Simulator dari penelitian sebelumnya dengan menambahkan outputan menjadi 10 sadapan yang apabila dibaca menggunakan ECG Recorder akan terbaca menjadi 12 chanel. Studi ini dibangun berdasarkan mikrokontroler Arduino dan beberapa rangkaian analog. Studi ini telah membuktikan bahwa keakuratannya layak digunakan untuk mengkalibrasi EKG Recorder. Di masa depan, penelitian ini dapat dibuat dan digunakan di klinik kecil di desadesa dengan biaya rendah.

\section{DAFTAR PUSTAKA}

[1] R. Achmad, Instrumentasi Biomedis, no 1. July. Yogyakarta: Graha Ilmu, 2014

[2] C. Caner and M. Engin, "The programmable ECG Simulator," J. Med. Syst., vol. 32, no. 4, pp. 355-359, 2008.

[3] G. M. Tani, P. C. Nugraha, and Syaifudin, "Simulasi ECG (Phantom electrocardiograph) Berbasis Mikrokontroler (Gregorius Mario Tani, Priyambada Cahya Nugraha, Syaifudin)," 2017.

[4] N. N. S. Malini, I. D. G. H. Wisana, and M. R. Makruf, "ECG Simulator," pp. 8-9, 2017.

[5] M. Z. Alamanda, A. Pudji, and M. R. Makruf, "Phantom ECG," pp. 5-11, 2018.

\section{Jurnal Teknokes, Jurusan Teknik Elektromedik, POLTEKKES KEMENKES SURABAYA dan IKATEMI}

